\title{
Notas e descrições em Oemini, Dodecosini e Elaphidionini (Coleoptera: Cerambycidae: Cerambycinae)
}

\author{
Maria Helena M. GALILEO ${ }^{1,3}$, Ubirajara R. MARTINS $S^{2,3}$ \\ RESUMO \\ Novas espécies são descritas em três tribos de Cerambycinae: em Oemini, Kalore minima sp. nov., do Brasil (Amazonas); em \\ Dodecosini, Olexandrella rafaeli sp. nov., do Brasil (Rondônia); em Elaphidionini, Curtomerus lingafelteri sp. nov. da Bolívia, \\ Mephritus apicepullus sp. nov., M. vescus sp. nov. e M. estoni sp. nov. as três do Brasil (Amazonas). Notas e novos registros são \\ fornecidos para Macroeme vittipennis (Melzer, 1934), Dodecosis nigricornis Martins \& Galileo, 1991 e Adiposphaerion rubrum \\ Martins \& Napp, 1992.
}

PALAVRAS-CHAVE: Kalore; Olexandrella; Curtomerus; Mephritus.

\section{Notes and descriptions in Oemini, Dodecosini and Elaphidionini (Coleoptera: Cerambycidae: Cerambycinae)}

\section{ABSTRACT}

New species are described in three tribes of Cerambycinae: Oemini, Kalore minima sp. nov., from Brazil (Amazonas); in Dodecosini, Olexandrella rafaeli sp. nov., from Brasil (Rondônia); in Elaphidionini, Curtomerus lingafelteri sp. nov. from Bolivia, Mephritus apicepullus sp. nov., M. vescus sp. nov. and M. estoni sp. nov. the three species from Brazil (Amazonas). Notes and records are given for Macroeme vittipennis (Melzer, 1934), Dodecosis nigricornis Martins \& Galileo, 1991, and Adiposphaerion rubrum Martins \& Napp, 1992.

KEYWORDS: Kalore; Olexandrella; Curtomerus; Mephritus. 


\section{INTRODUÇÃO}

Reunimos neste artigo a descrição de seis espécies novas de três tribos de Cerambycinae. Em Oemini, tribo revista por Martins (1997), tratamos de uma espécie de Macroeme Aurivillius, 1893, gênero exclusivamente sul-americano, que reúne seis espécies; no gênero Kalore Martins \& Galileo, 2006, descrevemos a segunda espécie e estendemos sua distribuição para a Amazônia brasileira.

Dodecosini é uma tribo com pequeno número de gêneros (quatro) e de espécies (seis) ocorrentes no Brasil e na Guiana Francesa. Uma espécie de Dodecosis Bates, 1867, D. nigricornis Martins \& Galileo, 1991, foi descrita com base em exemplar único e o holótipo depositado em instituição venezuelana; agora, a distribuição será ampliada para Brasil. Descrevemos uma espécie em Olexandrella Zajciw, 1959 que reúne duas espécies, uma procedente do Brasil e outra da Guiana Francesa.

Em Elaphidionini, descrevemos espécies novas nos gêneros Curtomerus Stephens, 1839 e Mephritus Pascoe, 1866. Curtomerus sempre foi um gênero de difícil alocação em tribo e também foi descrito diversas vezes com nomes diferentes. Já esteve incluído em Callidiopini (Lacordaire 1869; Sharp 1878) ou em Elaphidionini (Arnett 1962; Linsley 1963; Lingafelter 1998). Martins (2005) conservou-o em Elaphidionini, mas afirmou que sua posição deveria ser revista, pois Curtomerus reúne características que não se encontram em outros gêneros da tribo, como o antenômero III desarmado e subigual em comprimento ao IV e olhos restritos aos lobos inferiores. Descrevemos uma espécie nova em Curtomerus que também é excepcional na cor metálica dos élitros e na escultura do protórax. $\mathrm{O}$ gênero reúne oito espécies distribuídas desde os Estados Unidos, Antilhas e América do Sul. A espécietipo, Callidium luteum Stephens, 1831 = Callidium flavum Fabricius, 1775 = Curtomerus flavus (F., 1775), apresenta grande distribuição nas Américas e já foi introduzida no Havaí e em Taiti (Monné 2005).

Descrevemos três espécies do estado do Amazonas no gênero Mephritus Pascoe, 1866, que até agora reunia 15 espécies, Mephritus foi considerado sinônimo de Nephalius Newman, 1841 por Gounelle (1907), entretanto, Martins (2005) julgou ambos os gêneros válidos.

Citam-se as seguintes instituições ao longo do texto: Instituto Nacional de Pesquisas da Amazônia, Manaus (INPA); Facultad de Agronomia, Universidad Central de Venezuela, Maracay (FAUV); Museu de Ciências Naturais, Fundação Zoobotânica do Rio Grande do Sul, Porto Alegre (MCNZ); Museo Noel Kempff Mercado, Santa Cruz de la Sierra (MNKM); Museu de Zoologia, Universidade de São Paulo, São Paulo (MZSP).

\section{OEMINI}

\section{Macroeme vittipennis (Melzer, 1934)}

Neoeme vittipennis Melzer, 1934: 213, est. 14, fig. 1.

Macroeme vittipennis; Martins 1997: 56; Monné 2005: 415 (cat.).

Macroeme vittipennis geralmente tem colorido castanhoavermelhado com faixas longitudinais amareladas nos élitros: uma dorsal e uma junto à epipleura. No exemplar examinado, as faixas dorsais amareladas são muito indistintas, ficando o dorso quase inteiramente castanho-avermelhado, mas com faixa lateral bem evidente.

Material examinado. BRASIL, Amazonas: Presidente Figueiredo (Sítio Água Viva, AM 240, km 12), macho, 18-22. XII.2006, F.F. Xavier Fo, G.M. Lourido, P.K.M. Almeida \& D.M.M. Mendes col., luz mista (INPA).

\section{Kalore minima sp. nov.}

Figura 1

Etimologia. Latim, minima = menor; alusivo às pequenas dimensóes.

Descrição. Palpos maxilares amarelados, pouco mais longos que os labiais. Cabeça laranja-acastanhada. Fronte fina e esparsamente pontuada $(32 \mathrm{x})$. Região anterior do vértice esparsamente pontuada. Lobos oculares inferiores salientes. Escapo laranja-acastanhado, liso. Antenômeros basais pretos e os mais apicais castanho-avermelhados. Antenômero III com pelos esparsos nos lados interno e inferior. Antenas atingem o ápice dos élitros aproximadamente na ponta do antenômero VI.

Protórax laranja-acastanhado, levemente arredondado nos lados. Gibosidades pronotais ântero-laterais indistintas. Pronoto liso, com pelos pretos, longos e esparsos. Processo mesosternal triangular. Metepisterno glabro com pontos esparsos. Lados do metasterno com pontuação esparsa. Pro-, meso- e metasterno com pelos brancos, esparsos.

Élitros com a região central laranja-acastanhada e faixa preta, longitudinal, nos lados, do úmero até o ápice dos élitros; pontuados em toda a superfície, menos nas extremidades que são intumescidas e lisas; ápice dos élitros atinge a margem posterior do segundo segmento abdominal.

Fêmures alaranjados, fortemente pedunculados e clavados. Protíbias alaranjadas. Mesotíbias alaranjadas na base e escurecidas para o ápice. Metatíbias faltam.

Urosternitos alaranjados. Urosternito $\mathrm{V}$ e urotergito $\mathrm{V}$ com pelos pretos, moderadamente densos.

Dimensões, mm. Comprimento total, dos tubérculos anteníferos ao ápice do abdômen, 6,2; comprimento do 
protórax, 0,8 ; maior largura do protórax, 1,0; comprimento do élitro, 2,5; largura umeral, 1,4.

Material tipo. Holótipo macho, BRASIL, Amazonas: Manaus (Reserva Ducke, 26 km N), IX.1995, M.G.V. Barbosa col., "Plot C", Malaise (INPA).

Discussáo. $\mathrm{O}$ gênero Kalore foi descrito por Martins e Galileo (2006) para conter única espécie, $K$. asanga Martins $\&$ Galileo, 2006 da Bolívia. Kalore minima sp. nov. difere de $K$. asanga pela cabeça, escapo e protórax laranja-acastanhados; pronoto com duas gibosidades indistintas junto à constrição anterior; pro- e mesofêmures unicolores, alaranjados. Em $K$. asanga a cabeça, o escapo e o protórax são castanhoescuros; o pronoto apresenta cinco gibosidades e a central é longitudinal; os pro- e mesofêmures são alaranjados com o ápice acastanhado.

\section{DODECOSINI}

\section{Olexandrella rafaeli sp. nov.}

\section{Figura 2}

Etimologia. O epíteto é uma homenagem a José Albertino Rafael (INPA) pelo apoio durante a permanência dos autores em Manaus.

Descriçáo. Cabeça amarelada com faixa preta em cada lado, atrás dos lobos oculares superiores. Vértice $(25 \mathrm{x})$ muito fina e densamente pontuado. Tubérculos anteníferos acuminados, separados por sulco profundo. As antenas atingem as extremidades dos élitros aproximadamente, no meio do antenômero VII. Escapo preto, pontuado, sem sulco basal, pouco mais curto que o antenômero III. Este, preto, apenas mais curto que o IV, com pelos curtos e muito densos no lado externo e, no lado interno, franja de pelos esparsos e mais longos que a largura do artículo. Antenômeros IV-VI amarelo-acastanhados na base e gradualmente mais escuros para o ápice. Antenômeros VII-XII pretos. Antenômero XII não apendiculado.

Protórax com gibosidade discreta no meio dos lados. Pronoto amarelado com faixa central, longitudinal, preta; borda anterior estreitamente preta, muito fina e densamente pontuado e com pubescência muito esparsa. Faixa preta, larga nas partes laterais do protórax no limite com o prosterno. Prosterno amarelado; demais esternitos torácicos, pretos.

Élitros com os 2/3 anteriores amarelados e o terço apical preto; mancha preta, sutural, larga da base até pouco antes do meio e outra, menos contrastante, no quarto anterior da epipleura. Toda superfície elitral fina e densamente pontuada; uma costa, curta, indistinta, na regiấo central; extremidades com espículo sutural.

Fêmures amarelados com extremidades largamente pretas. Tíbias pretas. Tarsos castanho-amarelados. Urosternitos pretos.
Dimensóes mm. Comprimento total, 7,4; comprimento do protórax, 1,2; maior largura do protórax, 1,7; comprimento do élitro, 5,0; largura umeral, 1,4.

Material-tipo. Holótipo fêmea, BRASIL, Rondônia: Vilhena (12 65'55”S, 60²2'21”W), 25.IV.2006, J.A. Rafael $\&$ F.F. Xavier $\mathrm{F}^{\circ}$ col., armadilha luminosa (INPA).

Discussáo. Olexandrella rafaeli sp. nov. difere de $O$. serotina Zajciw, 1959 pelo colorido corporal, pelo desenho dos élitros amarelado com áreas pretas e pelas pernas amareladas com o terço apical dos fêmures e as tíbias, pretos. Além disso, não existem gibosidades bem desenvolvidas no centro do pronoto. Em O. serotina, o colorido é preto com a base da cabeça, protórax e escutelo laranja-avermelhados e, cada élitro, com mancha branco-amarelada, larga, no meio, sem atingir a sutura; o pronoto tem cinco gibosidades e as pernas são inteiramente pretas (Zajciw 1959). Distingue-se de $O$. frederici Dallens et al. 2010 pelo escapo inteiramente preto, antenômeros IV a VI amarelo-acastanhado na base e gradualmente mais escuro para o ápice, pelos lados do pronoto amarelados com faixa centro-longitudinal preta; pelos élitros amarelados com o terço apical, mancha larga sutural da base ao meio e mancha no quarto anterior da epipleura, pretos; pela carena indistinta no meio dos élitros; pelas tíbias pretas e pelos prosterno e urosternitos amarelados e demais esternos torácicos pretos. Em $O$. frederici, o escapo é alaranjado com o quarto apical preto, os antenômeros IV a VI são pretos, os lados do pronto são pretos e a faixa centro-longitudinal alaranjada, os élitros são pretos com as margens, faixa longitudinal no dorso e faixa pré-apical alaranjadas, o meio do dorso dos élitros tem duas carenas longitudinais, as tíbias são alaranjadas e a face ventral é inteiramente alaranjada.

\section{ELAPHIDIONINI}

\section{Curtomerus lingafelteri sp. nov.}

Figura 3

Etimologia. O nome específico é uma homenagem a Steven W. Lingafelter, cerambicidólogo do National Museum of Natural History, Washington e coletor do holótipo.

Descriçáo. Cabeça preta, densamente pontuada. Parte central do vértice com "carinulae" longitudinais (40x, com a cabeça transversal à fonte luminosa). Antenas pretas. Escapo pontuado. Escapo, pedicelo e flagelômeros basais com longos pelos brancos. Antenômero III subigual em comprimento ao IV, sem sulcos ou carenas.

Protórax preto, com a constrição basal mais acentuada que a apical. Pronoto com "carinulae" longitudinais no meio e com carenas minúsculas, circulares, ântero-lateralmente. Metade látero-anterior do pronoto e partes laterais do protórax com densa pontuação sexual. 
Élitros verde-azulados, metálicos; dois terços anteriores densamente pontuados; terço apical com pontos, gradativamente, mais esparsos; cobertos por pelos brancos, longos e moderadamente esparsos. Extremidades elitrais arredondadas.

Pernas pretas com longos pelos esbranquiçados. Fêmures pedunculados e fortemente clavados. Tíbias pretas, sem carenas.

Prosterno preto, brilhante, com finas rugas transversais. Mesosterno preto-avermelhado, pontuado. Mesepisternos finamente pontuados. Metepisternos com pubescência esbranquiçada, esparsa. Metasterno preto-avermelhado, escuro; lados pontuados. Urosternitos preto-avermelhados.

Dimensóes em mm. Comprimento total, 17,2; comprimento do protórax, 1,7; maior largura do protórax, 1,8; comprimento do élitro, 14,9; largura umeral, 2,2.

Material-tipo. Holótipo macho, BOLÍVIA, Santa Cruz: Província Florida ("Vicoquin area, above Achira, Road to Amboró", 1807'S 6348’W, 2050 m), 9-11.XI.2007, S. W. Lingafelter col., coleta diurna (MNKM).

Discussáo. As espécies sul-americanas do gênero Curtomerus Stephens, 1839 foram revistas por Martins (2005) e C. lingafelteri sp. nov. separa-se de todas as espécies conhecidas pelo colorido verde-azulado, metálico, dos élitros e pela presença das "carinulae" pronotais.

\section{Mephritus apicepullus sp. nov.}

Figura 4

Etimologia. Latim, apice = ponta; pullus = preto, alusivo ao ápice dos élitros.

Descriçáo. Cabeça preta. Fronte esparsamente pubescente. Vértice fina e densamente pontuado. Antenas atingem o ápice elitral na extremidade do antenômero VIII. Escapo preto com pontos ásperos. Pedicelo e flagelômeros vermelho-alaranjados. Antenômeros III a VI com espinho curto no ápice interno.

Protórax castanho-alaranjado; lados com tubérculo pouco projetado e arredondado no topo. Pronoto com cinco gibosidades pouco salientes. Superfície pronotal esparsamente pubescente, com pontos escassos e rasos.

Élitros alaranjados com o quarto apical preto. Pelos dos élitros castanhos e curtos, visíveis principalmente na metade apical; densamente pontuados nos três quartos anteriores e gradualmente mais esparsos para o ápice. Extremidades elitrais cortadas em curva com espinho externo.

Pernas alaranjadas. Metatarsômero I mais curto que II+III. Face ventral do corpo acastanhada, menos urosternitos IV e V, mais escuros; revestida por pubescência serícea fina e esparsa.

Dimensôes mm. Comprimento total, 12,6; comprimento do protórax, 2,1; maior largura do protórax, 2,0; comprimento do élitro, 9,5; largura umeral, 2,6.
Material-tipo. Holótipo macho, BRASIL, Amazonas: Fonte Boa (02³2'27”S 660.'08'W), 27.IX.2006, F.F. Xavier Fo col., Malaise (INPA).

Discussão. Pela chave para as espécies sul-americanas de Mephritus em Martins (2005), M. apicepullus é discriminada com $M$. destitutus Napp \& Martins, 1982. Distingue-se de M. destitutus, descrita de Mato Grosso e Goiás, pela cabeça, escapo e quarto apical dos élitros pretos, pelos élitros com pelos acastanhados e pelos fêmures mais lineares. Em $M$. destitutus a cabeça e o escapo sấo avermelhados e os élitros são alaranjados e unicolores, os pelos elitrais são esbranquiçados e os fêmures sáo pedunculados e fortemente clavados. Mephritus apicepullus assemelha-se a M. apicatus (Linsley 1935) pelo colorido dos élitros alaranjados com o quarto apical preto. Difere pela cabeça preta, pelas antenas vermelho-alaranjadas, exceto escapo preto, pelas pernas alaranjadas e pelo pronoto com lados subparalelos, pouco mais longo que largo. Em M. apicatus, a cabeça é amarelo-acastanhada, exceto a frente dos olhos; as antenas e as pernas são pretas a castanho-avermelhadas e o pronoto é transversal com lados oblíquos em direção à gibosidade lateral.

\section{Mephritus vescus sp. nov.}

Figura 5

Etmologia. Latim, vescus = pequeno, miúdo, alusivo ao aspecto corporal.

Descriçáo. Cabeça castanho-avermelhada com pubescência esbranquiçada, moderadamente densa. Fronte e vértice com pontuação fina, densa. Antenas atingem o ápice dos élitros no ápice do antenômero VII; inteiramente alaranjadas com áreas levemente castanho-alaranjadas no escapo e na extremidade dos antenômeros. Espinho dos antenômeros III a $\mathrm{V}$ pequeno, mais curto que a largura do ápice do artículo.

Protórax vermelho-alaranjado com espinho curto e agudo nos lados. Pronoto sem tubérculos, com gibosidades láterobasais; pontuação nos lados; pubescência moderadamente densa; centro-longitudinalmente com área glabra.

Élitros amarelo-alaranjados, unicolores; com alguns pontos, principalmente, na metade apical, avermelhados; cerdas longas, acastanhadas, mais concentradas na metade apical. Pontuaçáo elitral densa na metade anterior e gradualmente mais esparsa em direçáo ao ápice. Extremidades elitrais cortadas em curva com espinho externo.

Pernas amarelo-alaranjadas. Metatarsômero I mais longo que II + III. Face ventral alaranjada.

Dimensóes mm. Comprimento total, 8,5; comprimento do protórax, 1,7; maior largura do protórax, 2,0; comprimento do élitro, 6,0; largura umeral, 2,1.

Material-tipo. Holótipo macho, BRASIL, Amazonas: Manaus (Reserva Biológica de Cuieiras, base de apoio da 


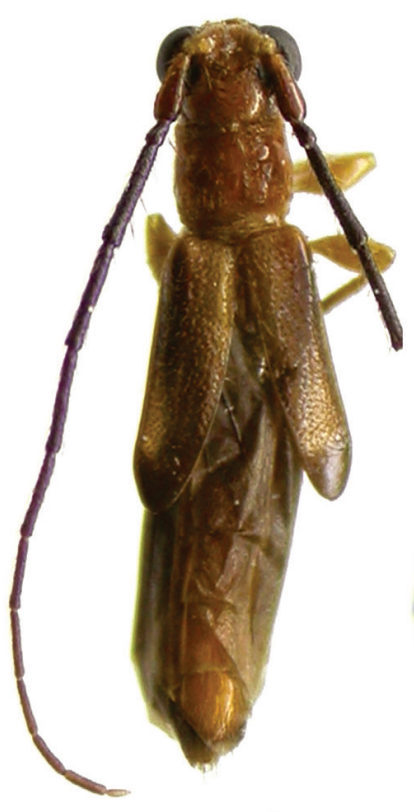

1

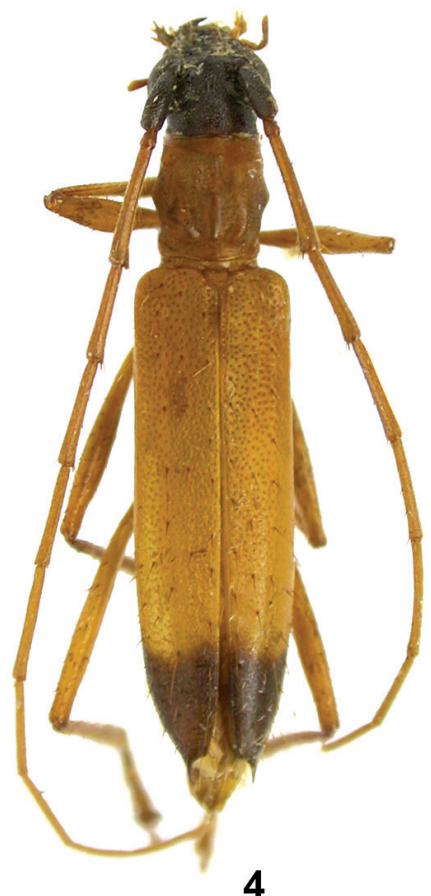

4
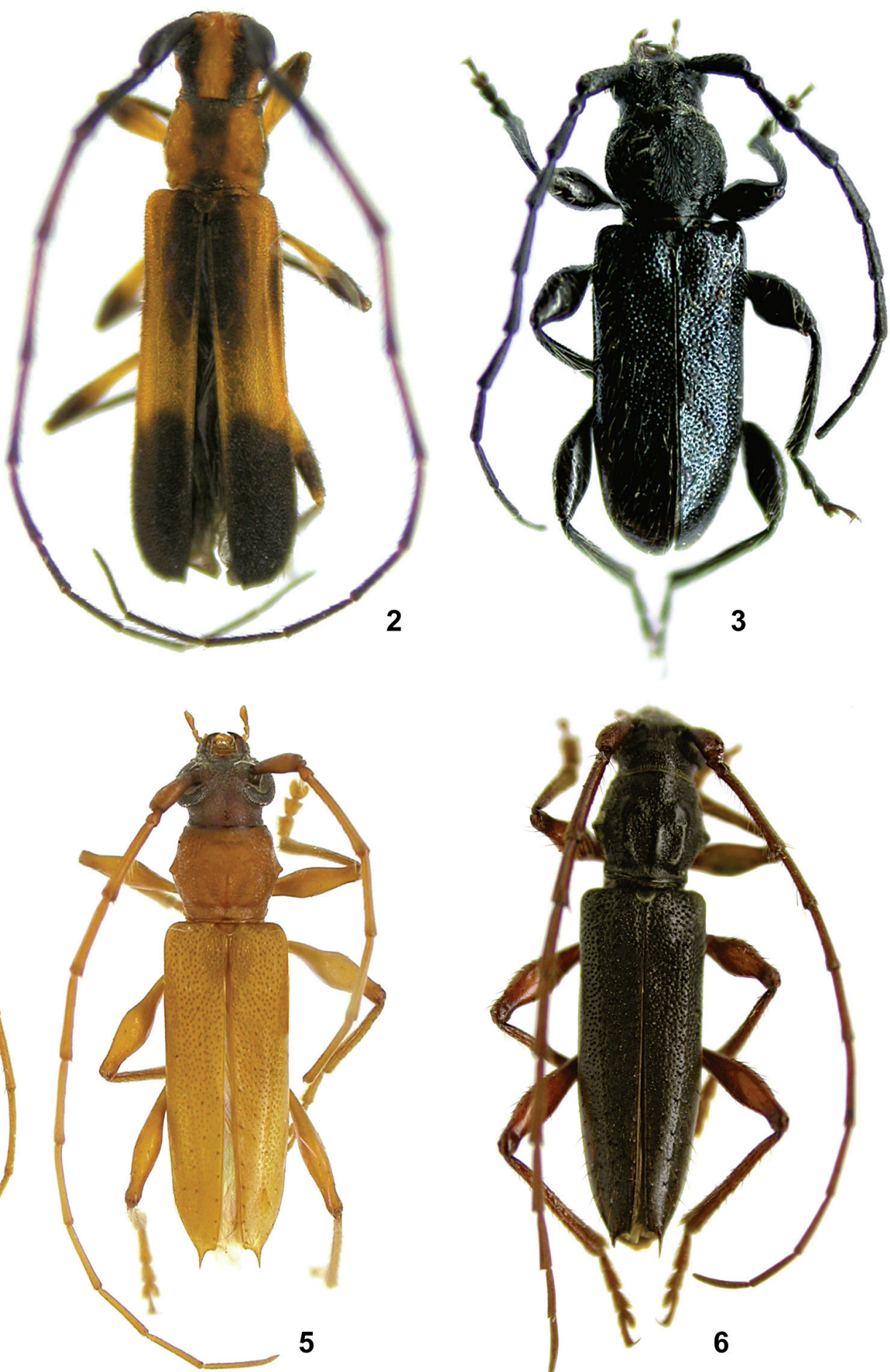

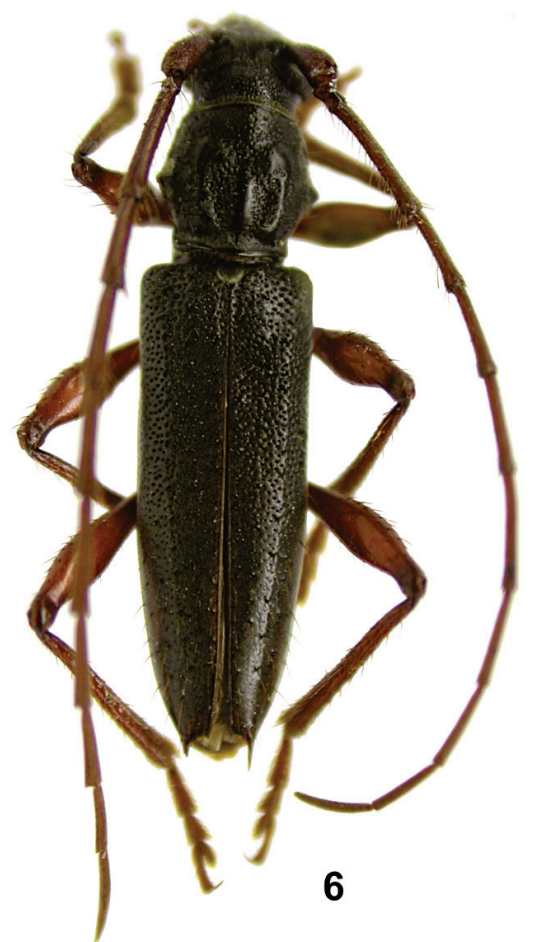

Figuras 1-6 - Habitus. 1. Kalore minima sp. nov., holótipo macho, comprimento 6,2 mm; 2. Olexandrella rafaeli sp. nov., holótipo fêmea, comprimento 7,4 mm; 3. Curtomerus lingafelteri sp. nov., holótipo macho, comprimento 17,2 mm; 4. Mephritus apicepullus sp. nov., holótipo macho, comprimento 12,6 mm; 5. Mephritus vescus sp. nov., holótipo macho, comprimento $8,5 \mathrm{~mm} ; 6$. Mephritus estoni sp. nov., holótipo macho, comprimento 13,2 mm. 
ZF/2, Torre de 45 m, 02035'21”S, 6006'55”W), 24.X.2007, J.A. Rafael; F.S.P. Godói; R.J.P. Machado; A. Filho \& R.R. Cavicchioli col., lençol-luz mista/BLB (INPA).

Discussão. Mephritus vescus sp. nov. também é discriminada na chave (Martins, 2005) no item $10 \operatorname{com} M$. destitutus e distingue-se pelas menores dimensôes (comprimento 8,3 $\mathrm{mm}$ ), pela cabeça castanho-avermelhada, mais escura que o protórax, pelo espinho lateral do protórax mais acuminado e pela presença de cerdas castanhas nos élitros. Em $M$. destitutus, as dimensôes são maiores (comprimento, 12,3 mm), a cabeça e o protórax são avermelhados, o espinho lateral do protórax é curto e rombo, as cerdas elitrais são branco-amareladas.

\section{Mephritus estoni sp. nov.}

Figura 6

Etimologia. O epíteto homenageia Jorge Médice de Eston que muito tem auxiliado um dos autores (URM) em informática.

Descrição. Cabeça, protórax e élitros castanho-escuros. Fronte e vértice com pontos grandes e próximos. Antenas atingem o ápice elitral no meio do antenômero IX. Antenas castanho-avermelhadas, escuras. Escapo com pontuaçáo moderada. Flagelômeros basais bicarenados e sulcados. Antenômeros III-VII com espinhos na extremidade do lado interno, gradualmente menores para o ápice.

Protórax com espinho lateral aguçado. Pronoto com cinco gibosidades, duas de cada lado muito próximas entre si; pontuação nos interstícios e esparsamente pubescente. Escutelo densamente revestido por pubescência esbranquiçada.

Élitros pontuados na metade basal; pontos gradualmente mais esparsos para o ápice. Pontos pilíferos ásperos na metade basal dos élitros. Extremidades elitrais com espinho longo no lado externo e espículo no ângulo sutural.

Pernas castanho-avermelhadas. Metatarsômero I apenas mais longo que II+III. Face ventral acastanhada, recoberta por pubescência serícea.

Dimensóes mm. Comprimento total, 13,2; comprimento do protórax, 2,7; maior largura do protórax, 3,0; comprimento do élitro, 9,2; largura umeral, 3,1.

Material-tipo. Holótipo macho, BRASIL, Amazonas: Manaus (Estrada ZF2), 1.X.2005, J.A. Rafael; F.F. Xavier Fo; R. Machado; A.A. Agudelo \& Y.K. Dantas col., armadilha de luz móvel (INPA).

Discussão. Pela chave de Martins (2005) para as espécies de Mephritus, M. estoni sp. nov. é discriminada junto com $M$. flavipes (Gounelle, 1909) e M. callidioides (Bates 1870). Difere de $M$. flavipes pelos élitros unicolores, com pontos ásperos e não contrastantes e pelo espinho elitral alongado. Em $M$. flavipes, que ocorre da Bahia a Santa Catarina, os élitros são bicolores com pontos contrastantes e os espinhos apicais dos élitros são curtos.

Distingue-se de $M$. callidioides pela cabeça e protórax inteiramente castanho-escuros, pelos pontos pilíferos dos élitros ásperos, pelas antenas e pernas castanho-avermelhadas. Em $M$. callidioides, o vértice e o protórax são avermelhados, as antenas e pernas são pretas e os élitros não possuem pontos ásperos.

\section{Adiposphaerion rubrum Martins \& Napp, 1992}

Adiposphaerion rubrum Martins \& Napp, 1992: 473, Figura. 15; Monné 2005: 180 (cat.).

A espécie foi descrita com base numa fêmea, cujas antenas atingem o quarto apical dos élitros, o antenômero III náo tem sulcos ou carenas. Examinamos um macho cujas antenas atingem o ápice elitral na base do antenômero X e o antenômero III é bicarenado e sulcado longitudinalmente.

Material examinado. BRASIL, Amazonas: Benjamin Constant (Sítio do Damião, 04²4’41”S, 7002’30”W), macho, 8-10.IX.2005, J.A. Rafael \& F.F. Xavier Fo col., armadilha luminosa (MZSP, doação do INPA).

\section{AGRADECIMENTOS}

A James Wappes (ACMB) e Augusto Loureiro Henriques (INPA) pelo empréstimo de material para estudo; a Eleandro Moysés, bolsista IC/CNPq/FZB (MCNZ) pelas fotografias e tratamento digital. Ao CNPq e FAPEAM pelo auxílio financeiro ao Programa de Apoio a Núcleos de Excelência (Pronex) projeto "Amazonas: diversidade de insetos ao longo de suas fronteiras (Processo 1437/207)" coordenado por José Albertino Rafael (INPA).

\section{BIBLIOGRAFIA CITADA}

Arnett, R.H. 1962. The beetles of the United States. Washington, Univ. of America. xi+1112 p.

Gounelle, E. 1907. Notes on the genera Sphaerion Serv., Nephalius Newm., Mephritus Pasc., Periboeum Thoms., and Stizocera Serv. Bulletin de la Société Entomologique de France, 1907: 238-244. (in French).

Lacordaire, J. T. 1869. Natural History of Insects. Genera of Coleoptera. Paris, Librairie Encyclopédique de Roret, 8: 1-552. (in French).

Lingafelter, S.W. 1998. The Genera of Elaphidiini Thomson 1864. Memoirs of the Entomological Society of Washington, 20: 1-118.

Linsley, E.G. 1963. The Cerambycidae of North America. Part IV. Taxonomy and classification of the subfamily Cerambycinae, tribes Elaphidionini through Rhinotragini. University of California Publication in Entomology, 21: 1-165.

Martins, U.R. (org.). 1997. South American Cerambycidae. Sociedade Brasileira de Entomologia, São Paulo. 217 pp. (in Portuguese) 
Martins, U.R. (org.). 2005. South American Cerambycidae. São Paulo, Sociedade Brasileira de Entomologia. 394 pp. (in Portuguese).

Martins, U.R.; Galileo, M.H.M. 2006. New taxa of Cerambycinae (Coleoptera, Cerambycidae) of the Neotropical Region. Iheringia, Ser. Zoologia, 96(2): 173-178. (in Portuguese, with abstract in English).

Martins, U.R.; Napp, D. S. 1992. Sphaerionini: new taxa, synonymy, keys and new combination. Revista Brasileira de Zoologia, 7(4): 459-476. (in Portuguese, with abstract in English).

Melzer, J. 1934. American longhorned beetles, mainly of Brazil, new or little known. Arquivos do Instituto Biológico, 5: 213-244. (in Portuguese).
Monné, M.A. 2005. Catalogue of the Cerambycidae (Coleoptera) of the Neotropical region. Part I. Subfamily Cerambycinae. Zootaxa, 94: 1- 765.

Sharp, D. 1878. On some longicorn Coleoptera from the Hawaiian Islands. Transactions of the Entomological Society of London, 1878: 201-210.

Zajciw, D. 1959. One tribe, three genera and three new species of longicorn from Brazil. (Col., Cerambycidae). Anais da Academia Brasileira de Ciências, 31(4): 605-616. (in Portuguese with abstract in English).

Recebido em 09/07/2010

Aceito em 06/09/2010 
